\title{
La transformación de la sociedad cooperativa
}

\author{
Fernando Sacristán Bergia \\ Profesor Titular de la Universidad Rey Juan Carlos
}

Recibido: $\quad$ 12.06.10

Aceptado: 28.06.10

Sumario: A. Introducción. B. Clases de transformación. C. Caracterización de la transformación de la cooperativa. 1. La exigencia del acuerdo de la Asamblea General. 2. La posición de los socios. 3. Los acreedores y la transformación. 4. El tratamiento de los Fondos no repartibles. D. En particular, sobre la transformación de Cooperativa en Sociedad Limitada.

Resumen: En el presente trabajo se aborda el estudio de la transformación de la sociedad cooperativa. Dedicando una atención especial a su caracterización, para lo que se analiza con un sentido critico la exigencia del acuerdo de la Asamblea General, el marco de la posición de socios y acreedores, así como el destino y tratamiento de los fondos no repartibles. El trabajo termina con la exposición del régimen de la transformación de la Cooperativa en sociedad Limitada.

Palabras clave: Cooperativas, transformación, Asamblea General, Sociedad de Responsabilidad Limitada.

Abstract: This paper focuses on the Cooperative's transformation process. The Author study the positions of creditors and members, and the general assembly decisions. This paper systematizes the transformation into private limited company.

Key words: Cooperative, transformation, General Assembly, Private Limited Company. 


\section{A. Introducción}

La trasformación consiste en un cambio de tipo social, sin modificar la identidad ${ }^{1}$. Con la transformación se produce un cambio en la forma societaria sin producirse en ningún momento discontinuidad o alteración de la titularidad de derechos y obligaciones (tal y como indica expresamente el art. 83 de la LCCM), es decir permaneciendo inalterada la identidad subjetiva de las relaciones de la sociedad con los terceros².

La posibilidad de trasformación de la cooperativa no ha sido admitida hasta fechas recientes en el ámbito del derecho cooperativo. Las razones que se daban en torno al rechazo de la transformación de las cooperativas, no estaban exentas de un claro componente ideológico, tratando de dificultar una huida del cooperativismo ${ }^{3}$. Entre otras, que había una barrera tipo que hace imposible la transformación de la cooperativa en otra sociedad, porque no se compadece con su esquema causal; que la transformación sería vehículo de fraude de ley, permitiría la transformación en otra figura, de la cooperativa, creada para aprovechamiento de ventajas fiscales y financieras, una vez conseguido el propósito ${ }^{4}$.

El reconocimiento de la transformación en la LCPV (Ley 4/1993) supuso un avance importante (arts. 85-86), pues en la LGC (Ley 3/1987 General de Cooperativas) sólo se le hacía referencia en la Disposición Transitoria Tercera, que contemplaba la transformación de SAT en Cooperativas Agrarias. El verdadero cambio de tendencia legislativa, viene provocado por la LSRL de 1995, que admite y establece el régimen para la transformación de sociedad limitada en cooperativa (art. 87.3), así como de la Cooperativa en Sociedad Limitada (art. 93), completándose su régimen posteriormente en el RRM (art. 218). Podemos destacar la importancia que, en su momento tuvo la Sentencia del Tribunal Supremo de 17 de marzo de 1999, en la que se afirmaba respecto de la posibilidad de transformación de una cooperativa, que no existe ninguna razón sólida para entender que la ausencia de una normativa especifica, en la legislación autonómica, reguladora del fenómeno venga a significar el rechazo de esta posibilidad.

La Ley 27/1999 de Cooperativas, en adelante la LCoop regula la transformación en el art. 69, dedicándola seis apartados, en los que se refiere, al ámbito subjetivo de la transformación, permitiendo

1 Como precisaba Girón, 1976, p. 352, «con conservación de la existencia e identidad.

2 En este sentido, León Sanz, 1997, p. 851.

3 Puede verse, Alfonso Sánchez, 2002, p. 30.

4 Entre otros, Rosembuj, 1995, p. 10; Nagore, 2001, p. 44. 
tanto la transformación de otros tipos sociales en cooperativas, como la de la propia cooperativa en otras sociedades, también al acuerdo de transformación, si bien remitiéndose a los términos y condiciones establecidos en la ley para la fusión (art. 69.1 LCoop). Respecto de la posición de los socios, se reconoce en el art. 69.2, de un lado, el derecho de separación, también en los mismos términos que para la fusión, y se establece la regla de la proporcionalidad para determinar su participación en la nueva sociedad. Además, limita los efectos de la trasformación de la cooperativa en algún tipo societario en el que respondan personalmente los socios de las deudas, sólo a aquellos socios que hayan votado a favor del acuerdo (art. 69.2 LCoop). Mientras que en el caso de transformación de otro tipo social en cooperativa, salvo consentimiento expreso de los acreedores, no se libera a los socios de su responsabilidad personal por las deudas anteriores (69.5 LCoop).

Hay también una referencia a la escritura de trasformación en sociedad cooperativa (art. 69.3 LCoop), que debe contener las menciones necesarias para constituir una cooperativa, un balance de transformación, y la relación de socios con su participación en el capital. Ello sin perjuicio del cumplimiento de la normativa por la que se rige la entidad transformada. Cuando la sociedad que se transforma estuviera inscrita en el Registro Mercantil, para su inscripción como cooperativa, es necesario un certificado sobre la inexistencia de obstáculos para la transformación (art. 69.4 LCoop).

Por último en el apartado $6 .^{\circ}$ del art. 69 LCoop, se establece expresamente que en el supuesto de transformación de la cooperativa en otro tipo, los saldos de los fondos de reserva obligatorios, el fondo de educación y cualesquiera otros fondos o reservas que estatutariamente no sean repartibles entre los socios, recibirán el destino previsto para el caso de liquidación de la cooperativa.

En la actualidad todas las leyes autonómicas regulan la transformación, las que lo han hecho más recientemente, son la LCCat, y la LFCN. Podemos apreciar distintas tendencias, desde un punto de vista de técnica legislativa, hay leyes que se refieren a la transformación en un único artículo LCAnd (108), LCCV (art. 79), LFCN (art. 59), aunque en algún caso se trata de artículos con muchos apartados, como ocurre con los 11 que dedica a la transformación el art. 84 de la LCCat. Normalmente no establecen una regulación muy detallada de la transformación, a excepción de la LCPV, la LCEx, o la LCCM, que dedica a la transformación 9 artículos (arts. 83 a 92), ofreciendo el régimen que se presenta como más completo, por plantear menos lagunas, y problemas de interpretación. 
En cuanto al contenido de la regulación en el marco de las Leyes autonómicas, encontramos dos tendencias, una que tiende a admitir la transformación, sin poner barreras, sin perjuicio de prever el destino de los fondos no disponibles en términos similares a la LCoop, así, entre otras, la LCCM, LCMur, LCCV, junto a esta tendencia. En otras leyes aumentan los obstáculos para la transformación, éstas últimas recurren a dos técnicas, que no siempre son concurrentes, exigen la justificación de razones económicas para la trasformación, así la LCPV, se refiere a la necesaria justificación de necesidades empresariales que exijan soluciones inviables en el sistema cooperativo (art. 85), necesidad que también debe justificarse en la LCCat (art. 84), art. 108.1 LCAnd, art. 75 LCEx. Y además, en el algún caso, se exige que el acuerdo de transformación sea autorizado, u homologado, como ocurre con el Consejo Andaluz de Cooperación, o del Consejo Superior de Cooperativas de Euskadi (arts. 85 LCPV, y 108 LCAnd). Habiéndose criticado esta técnica, por algún autor, en términos que compartimos, al entender la dudosa aptitud de órganos que han sido creados con carácter consultivo y asesor para asumir tal facultad; por la discrecionalidad con la que pueden llegar a decidir sobre la transformación, y en definitiva por la injerencia que supone en la esfera de la organización interna de una sociedad 5 . Incluso, se ha propuesto como formula para solventar estos controles, que no existen en el ámbito de la Lcoop, que la cooperativa autonómica puede convertirse en estatal ampliando su ámbito de actuación ${ }^{6}$.

En cuanto al propio contenido del régimen de la transformación previsto en la legislación autonómica, se ha dicho y con razón, que superan el detalle, y rigor técnico de la Ley estatal7 , pero dista mucho de presentarse como homogéneo, junto a las diferencias en orden a establecer obstáculos en torno a la transformación, pueden apreciarse otras. Entre las que destacamos las que afectan a la publicidad del acuerdo de transformación, mientras que en algunas leyes se exige la publicación en el Diario o Boletín Oficial de la comunidad, y en uno, o dos diarios, según los casos (entre otros: art. 84 LCCat, o el art. 108 LCAnd), en otras no se exige dicha publicidad (LCCM); o las que afectan al balance de transformación, que en algún caso puede sustituirse por el último balance de ejercicio, si no han transcurrido más de seis meses desde su publicación; y en alguna Ley se exige que sea auditado (art. 84 LCCAt, o LCMur), o que los interventores presenten un

\footnotetext{
5 Vid., Alfonso Sánchez, 2001, p. 39.

6 Puede verse, Nagore, 2001, p. 110.

7 En este sentido, Paniagua, 2005, p. 316.
} 
informe (art. 108 LCAnd). También hay diferencias relativas al reconocimiento del derecho de separación del socio, que afectan a aspectos como la legitimación, y el plazo de ejercicio (pueden compararse, a titulo de ejemplo los arts. 84 LCCat, el art. 108 LCand, con el art. 86 LCCM). La existencia de tales diferencias de tratamiento deben tenerse en cuenta para afrontar cada concreta operación de transformación, atendiendo a las particularidades previstas en la respectiva Ley aplicable.

La reciente Ley de Modificaciones Estructurales de las Sociedades Mercantiles Ley 3/2009, de 3 de abril, reconoce en el art. 4 que una sociedad cooperativa podrá transformarse en sociedad mercantil, y que una sociedad mercantil inscrita podrá transformarse en sociedad cooperativa. No obstante la anterior declaración, se deja las operaciones de modificación de las cooperativas fuera del ámbito de aplicación de la Ley al establecerse en el art. 2, que las modificaciones estructurales de las sociedades cooperativas se regirá por su específico régimen general. De manera que la LMESM no ha alterado el régimen aplicable a la transformación de la Cooperativa, probablemente por los problemas que plantea la competencia de las Comunidades Autónomas. Y lamentablemente se ha perdido la ocasión de armonizar el régimen aplicable a la trasformación de las cooperativas, además por otro lado, la derogación del art. 93 de la LSRL que regulaba la transformación de cooperativa en sociedad limitada, sólo puede entenderse como un descuido del legislador, olvidando que la LMESM no regula la citada operación.

Antes de entrar en un análisis de los elementos caracterizadores de la transformación, resulta conveniente hacer las siguientes consideraciones. Para determinar el régimen jurídico aplicable a una operación de transformación hay que tener en cuenta que la normativa aplicable a la cooperativa resultante o en transformación, debe coordinarse con la aplicable a la sociedad que se transforma en cooperativa, o en su caso, en la que se transforma la cooperativa.

El modelo cooperativo, como ya sabemos, presenta determinadas rigideces de régimen, que afectan a la posición del socio, en particular son claros los límites al acceso a los incrementos patrimoniales de la cooperativa. Y sin perjuicio de supuestos en los que detrás de la trasformación puedan darse razones que encuentren su fundamento en la adecuación del modelo empresarial, es normal que en su última justificación esté presente el interés del socio por capitalizar y mejorar su posición en relación con la dimensión patrimonial de la cooperativa. Esto nos lleva a plantear con realismo la trascendencia práctica de la trasformación en el ámbito cooperativo, para afirmar que serán más frecuen- 
tes aquellas transformaciones en las que claramente mejore la posición de los socios, supuestos estos de transformación hacia sociedades anónimas o limitadas, que aquellas otras en las que, su posición empeora, como ocurriría en la transformación en sociedad colectiva, comanditaria, o civil, en las que el régimen de responsabilidad del socio es por si sólo disuasorio de la transformación. Por otro lado, las mismas rigideces a las que antes nos referíamos, hacen que la operación de transformación en cooperativa no sea especialmente atractiva, porque normalmente, se optará por los tipos de sociedades de capital. Por ello, atendiendo a la realidad, debemos destacar la importancia de la trasformación de la cooperativa en sociedad limitada, que es además la que presenta un régimen jurídico, que aparece más desarrollado por nuestro legislador.

\section{B. Clases de transformación}

La LCoop permite tanto la transformación en cooperativa, como la de la propia cooperativa. El art. 69.1 LCoop, establece que cualquier asociación o sociedad que no tenga carácter cooperativo y las agrupaciones de interés económico podrán transformarse en sociedad cooperativa, al mismo tiempo que dispone que las sociedades cooperativas podrán transformarse en sociedades civiles o mercantiles de cualquier clase.

La transformación en sociedad cooperativa debe cumplir las siguientes condiciones, de acuerdo con lo dispuesto en la LCoop:

1. Que se cumplan los requisitos de la regulación sectorial, entendida como la legislación sectorial o especial que en su caso pueda resultar aplicable tanto a la sociedad origen, como a la cooperativa resultado de la transformación? ${ }^{8}$.

2. Que los miembros de las sociedades que se transforman puedan asumir la posición de cooperadores en relación con el objeto social previsto para la entidad resultante de la transformación (puede verse una crítica por entender que no parece acertado que los socios sólo puedan asumir la posición de cooperadores porque en la Cooperativa pueden participar también como socio colaborador o financiero, por lo que se propone interpretar la expresión cooperadores en sentido amplio?

8 Vid. Alfonso Sánchez, 2002, p. 59.

9 En este sentido, Alfonso Sánchez, 2002, p. 59. 
3. En el apartado $3 .^{\circ}$ del art. 69 , relativo a la escritura de transformación, se hace referencia al necesario cumplimiento de lo que exija la normativa de la entidad transformada. En definitiva, además de la necesidad de cumplir con los requisitos previstos en la LCoop, la transformación en cooperativa queda sometida al régimen aplicable a la forma social que se transforma ${ }^{10}$.

Por otro lado, como hemos indicado la LCoop permite que las cooperativas se transformen en sociedades civiles o mercantiles de cualquier clase. La regulación en el art. 69 y en el RRC es tan escasa, que debe atenderse a la normativa aplicable a la entidad resultante de la transformación ${ }^{11}$. No obstante, debe tenerse en cuenta que hay leyes autonómicas como la LCCM, LCEx, LCPV, que establecen una regulación más completa de la operación.

El art. 77.5 LCoop. se refiere a la posibilidad de transformar una cooperativa de segundo grado en otra de primero, «quedando absorbidas las cooperativas socios mediante el procedimiento establecido en la presente Ley», remisión que debe entenderse hecha tanto a las normas de la transformación como de la absorción ${ }^{12}$. Se ha afirmado que en este último supuesto, no hay en rigor una transformación sino una pérdida de grado ${ }^{13}$, y que no hay tampoco una absorción, a pesar de lo que parece exigible adoptar un acuerdo de transformación adoptado por la Asamblea General de la cooperativa de segundo grado y otro de absorción por la asamblea general de cada cooperativa socia en la de segundo gado ${ }^{14}$.

\section{Caracterización de la Transformación de la Cooperativa}

\section{La exigencia de acuerdo de la Asamblea General}

La transformación es una modificación estructural, que afecta a la posición de los socios, a la estructura de la sociedad, y que también puede afectar a los acreedores. La trasformación se produce por acuerdo de la Asamblea General de la cooperativa, que es en

10 Pueden verse, entre otros, Lázaro Sánchez, 2001, p. 302; Paniagua, 2005, p. 317.

11 Paniagua, 2005, p. 318, añade la aplicación como normas supletorias del RRM, y por analogía las normas de la LSA y la LSRL.

12 Paniagua, 2005, p. 319.

13 Paz Canalejo, 1999, p. 87.

14 Alfonso Sánchez, 2002, pp. 79-80. 
este caso el órgano que tiene competencia exclusiva para adoptar dicho acuerdo. Las particularidades de la operación de trasformación hace que tenga una identidad propia, no fácilmente identificable con otras modificaciones estructurales, pero, a pesar de ello, el legislador cuando se refiere al acuerdo de transformación, tiene la tendencia, tanto en la LCoop, como en la legislación autonómica, de remitir el régimen de dicho acuerdo, a lo previsto para la fusión (art. 69.2 LCoop), o para la modificación de estatutos (art. 79.1 LCCV, art. 108 LCAnd, art. 85.1 LCCM). Estás remisiones que se refieren tanto a la mayoría necesaria para su aprobación, como a los requisitos del acuerdo, plantean problemas de determinación de régimen, porque hay diferencias entre la transformación, y la fusión en la que hay extinción de sociedades, y creación de otras nuevas. Tampoco tiene mucho en común la trasformación de una sociedad con una mera modificación de sus estatutos, sino que constituye un verdadero cambio de tipo, que sin duda tiene otra dimensión.

Otras leyes autonómicas, optan por no hacer remisiones, evitando problemas de interpretación, como hacen la LCCat, o en la LCMur, que se limitan a expresar que el acuerdo debe de adoptarse por una mayoría de dos tercios, mayoría, que además, coincide con la exigida para la aprobación de la fusión de la sociedad, y para la aprobación de los estatutos (en todo caso, recordemos que resulta posible que los estatutos exijan una mayoría superior).

La remisión a las normas de la fusión o modificación de estatutos, llevan a aplicar al acuerdo de transformación, el régimen del derecho de información y de publicidad de aquellas, pero plantea lagunas sobre cual sea la documentación, e incluso el contenido de los acuerdos que deben someterse a la Asamblea. La determinación de tales aspectos, vendrá dada por la concreta operación de transformación de que se trate, pero parece oportuno, que además de la aprobación de la propia trasformación, se adopten otros acuerdos, como son en su caso, la aprobación de los estatutos de la nueva sociedad (si se incluyeran modificaciones que no vengan exigidas por el cambio de forma social, debe tenerse en cuenta que coinciden una trasformación con una modificación de estatutos), de las menciones necesarias para su constitución, la nueva posición de los socios (en su caso distribución del capital en la sociedad resultante), y la composición del órgano de administración de la sociedad resultante. También es necesario aprobar el balance de transformación, y el destino de los fondos no repartibles o disponibles, así como cualquier otra exigencia que respondiera a lo dispuesto en el régimen aplicable a la sociedad resultante de la transformación. 
Hay otros acuerdos que adquieren especial relevancia en torno a la transformación por su utilidad práctica, como ocurre con el otorgamiento de facultades para la presentación de la escritura de trasformación en el registro, o en su caso para solicitar las preceptivas autorizaciones $u$ homologaciones. También es oportuno autorizar expresamente para la subsanación de posibles defectos en la escritura de transformación, según la calificación del registro competente. Estás cuestiones, y las anteriores, deben preverse en la convocatoria de la Asamblea, tanto respecto del contenido del orden del día como de los anuncios de puesta a disposición de información.

Si se aprueba la transformación, a partir de ese momento se plantea un periodo de cierta transición. Desde que la asamblea aprueba la trasformación, hasta que su formalización concluye con la inscripción en el Registro Mercantil de la transformación, transcurre un espacio de tiempo que puede ser de varios meses, como consecuencia, en su caso, de la necesidad de respetarse el plazo previsto para el ejercicio del derecho de separación de los socios legitimados, y de que debe solicitarse del Registro de Cooperativas competente una certificación de inexistencia de obstáculos, en la que se indique cuales son los asientos que deben quedar vigentes. También hay que otorgar la escritura pública de transformación, y una vez presentada para su inscripción en el Registro Mercantil, podrían plantearse subsanaciones a la vista de la calificación registral, incluso en aquellas comunidades que exigen homologación o autorización previa del acuerdo, el lapso de tiempo será mayor.

En este periodo, la situación de la sociedad es compleja, porque la transformación no desplegará todos sus efectos hasta la inscripción en el Registro Mercantil, pero mientras tanto, tenemos un acuerdo societario de transformación vinculante que produce efectos, por lo que formalmente nos encontramos con una cooperativa, que concurre con una nueva forma social en formación. En previsión de este periodo, se pueden adoptar medidas que hagan este tránsito más sencillo, así ocurre con la delegación de facultades para la presentación y subsanación de la documentación relativa a la transformación, para lo que resulta oportuno que coincida el órgano de administración de la cooperativa con el de la nueva sociedad, agilizándose los trámites, evitando la duplicidad de firmas, y una vez superado el trámite puede cambiarse.

\section{La posición de los socios}

En esta aproximación a la caracterización de la transformación de la cooperativa, resulta conveniente referirse a la posición de socio. El cam- 
bio de tipo altera su posición, pudiendo afectar a aspectos tales como el régimen de responsabilidad, los derechos del socio (ej. régimen de transmisión de su participación), o incluso la valoración o interés económico de su participación. El socio participa en el proceso de trasformación a través de su derecho de información, y del voto (el art. 85.1 de la LCCM exige con acierto, que en la justificación de la propuesta de transformación los riesgos que, en su caso, supondría la transformación para los acreedores). En cuanto a la posición que ocupará en el socio la sociedad resultante de la transformación, el legislador ha establecido que debe cumplirse el criterio de proporcionalidad a la que tenían antes de la transformación (puede verse, entre otros, el art. 69.2 LCoop, o el art. 84.8 LCCat.)

Atendiendo a los cambios que la transformación puede producir en la posición del socio, el legislador ha creído conveniente proteger al socio disconforme por medio del reconocimiento de un derecho de separación o de baja, que como indicamos, se recoge con distinto ámbito de legitimación, plazos, y forma de ejercicio dependiendo de las distintas leyes autonómicas aplicables (ej, la LCCM, reconoce el derecho de separación, como baja justificada, al socio que vota en contra del acuerdo, a quien la sociedad debe comunicar por correo certificado el acuerdo, y desde su recepción estos tienen el plazo de un mes para ejercitar el derecho, mediante escrito por correo certificado. Y por su parte la LCAnd reconoce el derecho de separación, tanto a favor de los socios que han votado en contra, como a los que no asisten, derecho que deben ejercitar en el plazo de cuarenta días desde la última publicación realizada).

En cuanto a las consecuencias económicas del ejercicio del derecho de separación por parte del socio disconforme, es una constante en la legislación cooperativa reconocer la obligación de reintegrarle sus aportaciones al capital en las mismas condiciones que cuando se trata de una baja justificada (entre otros: art. 69.2 LCoop, art. 108.3 LCAnd, art. 94. 2 LCMur, art. 85.7 LCCat, o el art. 86 LCCM). Respecto de los plazos para la reintegración, que le corresponde a la sociedad resultante de la transformación, se aplicarán normalmente los de la baja justificada, si bien en alguna Ley, expresamente se remiten al plazo previsto en los estatutos, o al que acuerde la Asamblea General, percibiendo el interés legal del dinero por las cantidades aplazadas (art. 86 LCCM). Sin que falte, incluso, la previsión de la posibilidad para el socio de exigir garantías del reembolso de sus aportaciones, no pudiendo formalizarse la trasformación hasta que se haya garantizado (art. 84.7 LCCat).

No obstante lo anterior, el ejercicio del derecho de separación no siempre resultará conveniente para los intereses económicos del socio. Así en el caso de transformación de una cooperativa en sociedad limi- 
tada, el socio que se separa recibirá el reintegro de sus aportaciones al capital, pero si permanece en la sociedad limitada, y trasmite posteriormente sus participaciones recibirá un valor mayor, proporcional al valor de la sociedad. Circunstancia que desaconseja el ejercicio del derecho' ${ }^{15}$.

La trasformación no sólo afecta a los intereses económicos del socio, sino también puede afectar a su régimen de responsabilidad en el caso de trasformación de cooperativa en otra forma societaria en la que los socios tengan responsabilidades personales ilimitadas por las deudas sociales, o de la trasformación de una sociedad en la que los socios respondan personal e limitadamente de las deudas sociales, en cooperativa. En previsión de tales modificaciones en caso de trasformación de una sociedad personalista en cooperativa, el art. 69.3 LCoop, establece que la transformación no libera a los socios de su responsabilidad personal por las deudas contraídas con anterioridad al acuerdo, salvo consentimiento expreso de los acreedores a la transformación (previsión que se establece en la legislación autonómica, véase, entre otros, el art. 86.4 LCPV, o resulta directamente de aplicación por ausencia de previsión en la Ley autonómica). Y para el caso de trasformación de una sociedad cooperativa en otra, en la que los socios pasen a responder personalmente de las obligaciones sociales, la solución prevista es que pasarán a responder de la misma forma de las deudas anteriores a la trasformación (art. 69.5). Lo que, debe contemplarse en relación con lo dispuesto en el art. 69.2 in fine «el acuerdo de transformación en algún tipo de entidad, de cuyas deudas respondan personalmente los socios, tan sólo surtirán efectos respecto de los que hayan votado a favor del acuerdo». Esta previsión, tal y como ha indicado algún autor, causa una terrible perplejidad al interprete ${ }^{16}$, por los problemas de interpretación que plantea, llegándose a la conclusión de que la solución propuesta no consiste en que un acuerdo surta o no efectos respecto de todos o alguno de los socios, sino que significa que los socios que no han votado a favor de acuerdo quedan automáticamente separados de la sociedad ${ }^{17}$.

\section{Los acreedores y la transformación}

La transformación no afecta a la continuidad del régimen de responsabilidad de los socios por las deudas anteriores a la transforma-

15 Puede verse, Nagore, 2001, p. 75.

16 En este sentido, Lázaro Sánchez, 2001, p. 300.

17 Vid., Alfonso Sánchez, 2002, 153. 
ción. El acreedor no ve modificada su posición por la trasformación, puesto que sólo se alteraría el régimen de responsabilidad respecto de su crédito anterior al acuerdo de transformación, si el lo admite expresamente, y la transformación no afecta a las garantías que se hubieran otorgado a favor de los acreedores. La LCoop, en consecuencia, no establece a favor de los acreedores un derecho de oposición en los mismos términos que para la fusión y escisión, pero tal derecho si ha sido reconocido expresamente en alguna Ley autonómica, como ocurre, en la LCCat, art. 84.3, no pudiéndose llevar a efecto la transformación hasta que se hayan asegurado los derechos de los acreedores que se opongan, sin que estos puedan oponerse al pago aunque se trate de créditos no vencidos.

\section{El tratamiento de los Fondos no repartibles}

Una de las particularidades de la transformación de la cooperativa, que puede llegar a constituir uno de sus principales obstáculos desde el punto de vista del coste económico, en el destino de los fondos irrepartibles. El art. 69.6 LCoop, en términos similares a lo previsto en la legislación autonómica (art. 84.11 LCCat, art. 59.3 LFCN, art. 94.2.d LCMur) señala que «en el supuesto de transformación de una sociedad cooperativa en otro tipo de entidad, los saldos de los fondos de reserva obligatorio, el fondo de educación y cuales quiera otros fondos o reservas que estatutariamente no sean repartibles entre los socios, recibirán el destino previsto en el artículo 75 de esta ley para el caso de liquidación de la cooperativa» (aspecto este ya comentado en el capitulo correspondiente a la liquidación) ${ }^{18}$.

En principio la cooperativa, debe dar el destino previsto a los Fondos no repartibles, para lo que tendrá que hacer efectivo su importe conforme a la legislación que resulte aplicable. En el marco de algunas leyes autonómicas, cabe que se le de al importe de dichos fondos el

18 En el marco de la legislación autonómica se establece la misma regla, si bien podemos encontrar matices de unas Leyes a otras, que deben tenerse en cuenta. Así, en el art. 108.4 de la LCAnd, se dispone «El activo de la cooperativa que exceda del importe del capital social actualizado, en su caso, y de los fondos voluntarios repartibles que puedan existir, el Fondo de reserva Obligatorio y el Fondo de educación y Promoción se pondrán a disposición de la Administración de la Junta de Andalucía, que lo destinará, exclusivamente, a los fines de educación y promoción de las sociedades cooperativas andaluzas, a través del Consejo Cooperativo Andaluz.», añadiendo a continuación una salvedad para el caso en hubiera dispuesto en los estatutos la repartibilidad parcial del Fondo de Reserva Obligatorio. 
tratamiento de un titulo de cuenta en participación ( LCPV art. 85.4), o que se ofrezca la posibilidad de optar por el sistema de cuenta de participación de la sociedad resultante o de un crédito retribuido al interés de tres puntos sobre el legal del dinero, que se reembolsará en plazo de cinco años para el Fondo de Reserva Obligatorio y las reservas voluntarias que fueran irrepartibles (la LCCV dispone en el art. 79.5 que se debe hacer efectivo el valor de la reserva obligatorio, o se acreditará como crédito retribuido, mientras que para el importe del Fondo de Formación y Promoción, establece que se estará a lo dispuesto en los estatutos, y en su defecto para lo previsto en el caso de liquidación, en el mismo sentido puede verse el art. 87 LCCM).

\section{En particular sobre la transformación de Cooperativa en Sociedad Limitada}

Atendiendo a lo expuesto hasta este debemos destacar la importancia de la transformación de la cooperativa en sociedad de responsabilidad limitada, por ser la operación que normalmente interesará más a los socios, y porque atendiendo a su régimen jurídico será también la que ofrezca mayores seguridades al estar el proceso definido por el legislador.

En cuanto al marco jurídico aplicable a la transformación de una cooperativa en sociedad limitada, la primera cuestión a dilucidar es la determinación de la ley que rige el régimen de la cooperativa que se va a transformar. Como ya se indicó, en el marco de la legislación autonómica de cooperativas, puede ocurrir que la ley aplicable presente un régimen completo sobre la transformación, incluyendo normas sobre la transformación en limitada, como ocurriría con la LCCM, y también cabe, que nos encontremos con una Ley autonómica que no tenga normas especificas sobre la trasformación en sociedad limitada, o incluso, en la que las normas generales sobre la transformación sean incompletas.

Además debe tenerse en cuenta que la LSRL dedicaba el artículo 93, que ha sido derogado por la Ley de Modificaciones Estructurales, a la transformación de cooperativas en sociedad limitada, estableciendo expresamente en el apartado 3 que, en defecto de normas específicamente aplicables la transformación, quedaba sometida a lo dispuesto en el citado precepto ${ }^{19}$. Si bien, permanece en vigor el

19 En el artículo 93 LSRL encontrabamos manifestaciones generales respecto de la trasformación de la cooperativa en sociedad limitada, y reglas específicas sobre el acuerdo de transformación, y la escritura de trasformación. En relación con los aspec- 
art. 218 del RRM que contempla específicamente esta operación de transformación. En consecuencia el régimen previsto en el RRM cobra trascendencia para determinar el contenido del régimen legal aplicable a la trasformación, siendo de aplicación directa en aquellos casos en los que la legislación autonómica no tenga un régimen especifico aplicable, y en otros, atendiendo a su contenido, deben completarse las lagunas que en su caso presente la legislación autonómica con lo dispuesto en el RRM, que constituye en todo caso, incluso cuando el régimen autonómico sea más completo (LCPV, LCEx, LCCM), un claro criterio de interpretación de la legislación autonómica, atendiendo al hecho de que la trasformación debe inscribirse finalmente en el Registro Mercantil. El propósito de este apartado es referirnos al régimen previsto en el RRM, que debe aplicarse en cada operación de transformación de acuerdo al criterio expuesto, dependiendo por tanto de cual sea la legislación cooperativa aplicable.

En relación con el acuerdo de transformación, se establece que debe adoptarse según lo dispuesto para la modificación de los estatutos de la cooperativa que se transforma. $Y$ en cuanto a la escritura de transformación se exige que contenga las menciones necesarias para la constitución de una sociedad limitada; que se acompañe de un balance cerrado al día anterior al acuerdo de transformación, y de un balance final cerrado el día anterior al otorgamiento de la escritura. También debe acompañarse a la escritura la certificación del registrador de cooperativas competente sobre la no existencia de obstáculos para la transformación, extendida en los términos previstos en el propio art. 218.3 RRM, y atendiendo al reconocimiento en la legislación aplicable del derecho de separación se debe indicar, en su caso, quienes han hecho uso del mismo, y el capital que representen.

Respecto del contenido de la escritura de transformación, el art. 218 del RRM añade que debe constar, en su caso, el consenti-

tos generales, encontramos manifestaciones que no están expresamente previstas en el RRM, se reiteraba que los fondos que no sean repartibles tienen el mismo destino que en la disolución de la sociedad cooperativa; y además se establece que salvo que los acreedores hubieran consentido expresamente la transformación, la responsabilidad personal de los socios que la tuvieren, subsistirá en los mismos términos por las deudas sociales anteriores a la transformación. Se trata de una responsabilidad que prescribirá a los cinco años desde la publicación de la transformación en el BORME (por lo que el art. 93 se está refiriendo a la publicación del anuncio de la inscripción del acuerdo de transformación en el Registro Mercantil, y al anuncio o anuncios, que en su caso, pudiera exigir la legislación autonómica respecto del acuerdo de transformación, que no se publican en el BORME). Esta responsabilidad se establece expresamente en el art. 21.2 de la LMESM. 
miento de los socios que tengan en la cooperativa algún tipo de responsabilidad personal por deudas sociales; la manifestación de los otorgantes, bajo su responsabilidad, de que el patrimonio cubre el capital social quedando éste totalmente desembolsado, y si los acreedores sociales hubieran consentido expresamente la transformación, también hay que hacer referencia a los socios que hubieran ejercitado en su caso, el derecho de separación. También debe indicarse cuales han sido las normas que han aplicado al acuerdo de transformación, así como el destino que se haya dado a los fondos o reservas que tuviere la cooperativa. Y además, si la legislación cooperativa aplicable exige algún tipo de publicidad respecto del acuerdo de transformación, deben acompañarse los ejemplares de las publicaciones en que la misma se hubiere realizado.

La exigencia de cumplir con las menciones necesarias para la constitución de una sociedad limitada, determina parte del propio contenido del orden del día de la asamblea que trata la trasformación, pues debe completarse atendiendo a aquellas, para posteriormente dejar constancia de las mismas en la escritura de transformación. En consecuencia, de acuerdo con lo dispuesto en el art. 12 de la LSRL, también deben incluirse en la escritura de transformación de la cooperativa: los estatutos de la sociedad limitada resultado de la transformación; la identidad de los socios y las participaciones asignadas a cada uno; la determinación del modo en que se organice la administración, la identidad de la persona o personas que se encarguen inicialmente de la administración, y en su caso, los pactos y condiciones que los socios juzguen conveniente establecer, siempre que no se opongan a las Leyes ni contradigan los principios configuradores de la sociedad limitada.

Antes de convocar la asamblea que trate la transformación, debe prepararse la documentación que hay que poner a disposición de los socios con la convocatoria de la asamblea. La remisión que hace el art. 69 Lcoop a las normas previstas para la fusión ${ }^{20}$, que establecen que se ponga a disposición de los socios el proyecto de modificación. Para determinar cual es la documentación necesaria, debe tenerse en

20 En el ámbito de legislación autonómica, como ya indicamos, respecto del acuerdo de transformación son constantes la remisiones a lo dispuesto para la fusión, o para la modificación de estatutos, planteando generalmente problemas de interpretación sobre la documentación necesaria, excepción hecha de alguna ley autonómica que si se refiere expresamente a la necesidad de un informe del órgano de administración, como ocurre con la LCCM; Por su parte, Nagore, 2001, p. 65, afirma que parece conveniente, aunque no legalmente exigible, que con la convocatoria se ponga a disposición de los socios, un proyecto de transformación, un informe sobre su conveniencia, un balance de transformación y los nuevos estatutos sociales. 
cuenta que se trata de un proyecto de transformación, por lo que entendemos que debería incluirse un informe relativo a la justificación del tipo de transformación propuesta, y el proyecto de los estatutos de la sociedad resultado de la transformación.

Por otro lado, atendiendo a la descoordinación existente entre los distintos Registros de Cooperativas y el servicio de denominaciones del Registro Mercantil Central, y en consecuencia, para ahorrar trámites innecesarios, resulta conveniente con carácter previo al acuerdo de transformación reservar la denominación de la futura sociedad imitada, pues la certificación de denominación debe acompañarse a la escritura de transformación como si se tratara de la constitución de una sociedad limitada (en su caso, podría solicitarse en el Registro Mercantil, la reserva de varias denominaciones, para plantear en la asamblea, la opción por una de ellas).

En consecuencia, atendiendo a lo expuesto, el orden del día de una Asamblea General convocada para tratar la transformación de una cooperativa, en sociedad de responsabilidad limitada, debe contener junto al punto relativo al acuerdo de transformación, otros que se refieran a la aprobación del balance de transformación; la aprobación del destino de los fondos no repartibles; la aprobación de los estatutos de la sociedad limitada21; la aprobación de las manifestaciones necesarias para la escritura de transformación, relativas al patrimonio, y adjudicación de participaciones sociales; el nombramiento del órgano de administración. También resulta conveniente, tratar en un punto la delegación de facultades para realizar todos los trámites necesarios para la formalización e inscripción de la transformación en el Registro Mercantil, incluyendo expresamente, facultades para la adecuación de la cifra de capital, y del reparto de las participaciones sociales para el supuesto de ejercicio del derecho de separación por algún socio 22 .

El orden del día debe completarse con las menciones legal y estatutariamente exigidas con carácter general para la convocatoria de la Asamblea, incluyendo entre otras, las relativas a la constitución de la asamblea, y el nombramiento de la mesa, ruegos y preguntas, aprobación del acta, así como, en su caso, los anuncios relativos a la

21 Cuando se incluyan modificaciones como la ampliación del objeto social, que no vengan impuestas por el acuerdo de transformación, debe tenerse en cuenta el régimen previsto para la modificación de estatutos, en este mismo sentido: Alfonso Sánchez, 2002, p. 249.

22 Sobre este último aspecto, Nagore, 2001, p. 69, por su parte afirma que debe entenderse que los otorgantes de la escritura están autorizados a hacerlo, porque otra interpretación obligaría a celebrar otra reunión de socios para reducir el capital. 
puesta a disposición de los socios de la documentación que se va a someter a la Asamblea (informe justificativo de la propuesta, proyecto de estatutos de la sociedad resultante, a lo que algún autor añade, la procedencia de acompañar un proyecto del balance de transformación ${ }^{23}$. Respecto de la convocatoria el funcionamiento de la Asamblea se aplican las normas generales, debiendo respetarse el régimen de mayorías legal o estatutariamente previstos para la adopción de los acuerdos.

Una vez aprobado el acuerdo de transformación, y antes de otorgar la escritura pública, debe solicitarse del registro competente el certificado de no existencia de obstáculos para la inscripción en el Registro Mercantil de la transformación (actuación que se complica, y retrasa en aquellas Comunidades Autónomas en las que el acuerdo de transformación exige homologación o autorización previa). Además, antes de otorgar la escritura de transformación debe dejarse transcurrir el plazo previsto para el ejercicio del derecho de separación de los socios, excepto en el supuesto en que el acuerdo se hubiera adoptado por unanimidad.

Respecto del momento en que debe darse a los fondos no repartibles el destino previsto en la ley, practicando los correspondientes abonos, no resulta claro en la Ley (sin perjuicio de que en el ámbito de la legislación autonómica podamos encontrar alguna norma que lo disponga expresamente, como ocurre en el Reglamento de Cooperativas del País Vasco, que establece en el art. 59.3.g, que se debe acreditar la aplicación del Fondo de educación y Promoción...). Algún autor ha manifestado que la obligación de abono de las cantidades correspondientes a los fondos irrepartibles a las entidades beneficiarias corre a cargo de la cooperativa y no de la sociedad resultante y que habrá de ser previa al otorgamiento de la escritura ${ }^{24}$. Entendemos que la necesidad de expresar en la escritura el destino de los fondos, no exige el abono previo a su otorgamiento, sino que sería suficiente con la manifestación del destino que se les dará, para lo que en su caso es oportuno remitirse a lo acordado por la propia asamblea (siempre y cuando, insistimos, no exija expresamente otra cosa la legislación autonómica que resulte aplicable). Por otro lado, la condición que debe darse para aplicar

23 Así entre otros: Alfonso Sánchez, 2002, p. 244, lo que llama la atención, porque se trata de un balance que se cierra con fecha del día anterior a la celebración de la asamblea.

24 En este sentido, Alfonso Sánchez, 2002, p. 201, sobre la base de la necesidad de expresar el destino que se le haya dado a estos fondos en la escritura de transformación. 
tal destino a los fondos irrepartibles es la transformación de la cooperativa, y hasta que no se inscriba en el Registro Mercantil la escritura de transformación pueden surgir obstáculos, como ocurriría con una calificación registral de un defecto insubsanable, que impidiese la finalización del proceso de transformación, y por tanto la eficacia de los acuerdos adoptados 25 .

\section{Bibliografía}

Alfonso Sánchez, R., «La transformación de la Sociedad Cooperativa», Ed. De Derecho Reunidas, 2002.

EMBID, J.M. «Notas para el estudio de las modificaciones estructurales de la sociedades mercantiles», en VV.AA., Derecho Mercantil de la Comunidad Económica Europea, Estudios en Homenaje a José Girón Tena, Ed Cívitas, 1991.

GIRÓN TenA, J., «Derecho de sociedades, t. I, Parte General. Sociedades colectivas y comanditarias», 1976.

Lazaro Sánchez, E.: "Fusión, escisión, transformación», en VV.AA., La Sociedad Cooperativa en la Ley 27/1999. de 16 de julio de Cooperativas, Ed. Comares, 2001.

LEÓN SANZ, "Fusión, transformación y otras modificaciones estructurales de las sociedades cooperativas», RdS, 1997.

MACIAS RUANO, J.L., "Consideraciones críticas sobre la fusión, escisión y transformación en la Ley 27/1999, de 16 de julio, de cooperativas», Revesco, n. ${ }^{\circ} 78,2002$.

NAGORE, I, «La transformación de la sociedad cooperativa en sociedad de responsabilidad limitada», Ed. Dykinson, 2001.

Paniagua Zurera, M., "La sociedad Cooperativa. Las sociedades mutuas de seguros y las mutualidades de previsión social», en Tratado de Derecho Mercantil, Dir. Olivencia, Fernández Novoa, Jiménez de Parga, Ed. Marcial Pons, 2005.

Rodríguez Artigas, F.: «Escisión», en Comentario al Régimen Legal de las Sociedades Mercantiles, t. IX, vol. 3, Dir. Uria/Menéndez/Olivencia; Ed Cívitas, 1993.

Rosembus, T, «La transformación de la cooperativa en la nueva Ley de Sociedades de Responsabilidad Limitada», Compartir, n. ${ }^{\circ}$ oct/nov/dic de 1995.

25 La inscripción de la transformación tiene carácter constitutivo, De Eizaguirre, 1997,p. 882. 